\title{
PEMAPARAN ELEMEN EMOSI BERBENTUK KINESIK SEBAGAI KOMUNIKASI BUKAN LISAN WATAK DALAM HIKAYAT PUTERA JAYAPATI DAN HIKAYAT SI MISKIN
}

\section{(Displaying of Emotional Kinesics Elements as Non-Verbal Communication by Characters in Hikayat Putera Jayapati and Hikayat Si Miskin)}

\author{
Nadiatul Shakinah Abdul Rahman \\ nadiatul@uum.edu.my
}

Pusat Pengajian Bahasa, Tamadun dan Falsafah, Universiti Utara Malaysia.

To cite this article (Rujukan artikel ini): Nadiatul Shakinah Abdul Rahman (2021). Pemaparan elemen emosi berbentuk kinesik sebagai komunikasi bukan lisan watak dalam Hikayat Putera Jayapati dan Hikayat Si Miskin. Malay Literature, 33(2), 43-68. http://doi.org. 10.37052/ml34(1)no3

\begin{tabular}{|c|c|c|c|c|c|c|}
\hline $\begin{array}{l}\text { Received: } \\
\text { Peroleh: }\end{array}$ & $31 / 3 / 2021$ & $\begin{array}{l}\text { Revised: } \\
\text { Semakan }\end{array}$ & $9 / 5 / 2021$ & $\begin{array}{l}\text { Accepted: } \\
\text { Terima: }\end{array}$ & $11 / 5 / 2021$ & $\begin{array}{l}\text { Published online: } \\
\text { Terbit dalam talian: }\end{array}$ \\
\hline
\end{tabular}

\begin{abstract}
Abstrak
Manusia berkomunikasi menggunakan medium lisan seperti pertuturan dan penulisan. Komunikasi bertujuan untuk menyalurkan maklumat, pemikiran, sikap dan emosi seseorang individu kepada individu atau kelompok yang lain. Komunikasi amat penting dalam kehidupan manusia kerana tanpa komunikasi manusia tidak dapat bertukar atau berkongsi pandangan, maklumat, pemikiran, perasaan dan emosi. Sehubungan itu, manusia akan saling berkomunikasi antara satu sama lain. Komunikasi terbahagi kepada dua bentuk, iaitu secara lisan atau bukan lisan. Komunikasi lisan seperti bahasa lisan manakala, komunikasi bukan lisan seperti bahasa tulisan, bahasa isyarat, lukisan, kinesik, kronemik, paralinguistik, dan prosemik. Dalam konteks kajian ini, pemaparan elemen emosi dalam naskhah Melayu tradisional adalah sebagai salah satu bentuk komunikasi manusia yang diperlihatkan menerusi watak-watak di dalamnya. Kajian ini akan memfokuskan pemaparan elemen emosi
\end{abstract}

(C) Dewan Bahasa dan Pustaka. 2021. This work is licensed under the term of the Creative Commons Attribution (CC BY) (http://creative commons.org/licenses/by/4.0/) ISSN: 0128-1186 e-ISSN: 2682-8030 
berbentuk kinesik, iaitu komunikasi bukan lisan watak dalam naskhah Melayu tradisional. Kajian ini menggunakan kaedah analisis data, iaitu analisis terhadap kandungan naskhah Melayu tradisional seperti Hikayat Putera Jayapati dan Hikayat Si Miskin. Selain itu, kajian ini juga akan menggunakan Teori Kognitif Arnold-Ellis bagi mengukuhkan hujahan kajian. Hasil kajian mendapati bahawa antara pemaparan elemen emosi berbentuk kinesik diperlihatkan menerusi isyarat mata, wajah, sentuhan, gerakan anggota badan dan tingkah laku luar kawalan. Kajian ini dapat membuktikan bahawa manusia berkomunikasi antara satu sama lain menerusi ekspresi emosi dan tingkah laku mereka menerusi watak-watak yang dipaparkan dalam naskhah Melayu tradisional.

Kata kunci: Bukan Lisan, emosi, kinesik, komunikasi, naskhah Melayu

\begin{abstract}
Humans communicate by using verbal mediums such as speech and writing. The purpose of communication is to spread the information, thoughts, feelings and an individual's emotions. Communication is vitally important in human life because without communication, we as human beings are unable to exchange or share views, information, thoughts, feelings and emotions. It is for this reason that humans communicate with each other. Communication is divided into two forms namely, verbal or non-verbal. Verbal communication is oral, while non-verbal communication includes written language, sign language, drawings, kinesics, chronemics, paralinguistics and proxemics. In the context of this study, the display of emotional elements in Malay manuscripts is a form of human communication through the characters in these manuscripts. Because of that, this study will focus on the display of emotional elements in the form of kinesics as the non-verbal communication of characters in old Malay manuscripts. This study employs the data analysis method, in analysing the content of old Malay manuscripts such as Hikayat Putera Jayapati and Hikayat Si Miskin. Other than that, this study will use Arnold-Ellis's Cognitive Theory to strengthen the argument of the study. The results of the study found that between the emotional kinesics elements are eye gestures, facial expressions, touch, limb movements and out-of-control behaviours. Thus, this study proves that humans communicate with each other through the expressions of emotions and behaviours as displayed by the characters featured in the Malay manuscripts.
\end{abstract}

Keywords: Non-verbal, emotions, kinesics, communication, Malay manuscripts 


\section{PENDAHULUAN}

Emosi berasal daripada kata akar bahasa Latin movere yang bermaksud menggerakkan atau bergerak. Kemudian ditambah dengan awalan "e-" untuk memberi erti bergerak menjauh. Makna ini menyiratkan kesan bahawa kecenderungan bertindak merupakan hal mutlak dalam emosi (M. Darwis Hude, 2006:16). Berdasarkan pandangan ini memperlihatkan bahawa kata movere apabila ditambah dengan awalan "e-" akan menjadi emovere. Dalam hal ini, Othman dan Abd. Aziz (2005: 388) menjelaskan bahawa kata emovere secara harfiah bermaksud untuk keluar, yang merujuk keadaan yang dilalui oleh manusia seperti perubahan pada proses fisiologi diri dan psikologi.

Selain itu, menurut Goleman (2006: 289) emosi merujuk perasaan dan pemikiran, keadaan psikologi dan biologi serta pelbagai kecenderungan untuk bertindak. Malah, M. Darwis Hude (2006: 18) juga berpendapat bahawa emosi merupakan suatu gejala psikofisiologi yang menimbulkan kesan pada persepsi, sikap dan tingkah laku, serta meniru dalam bentuk ekspresi tertentu. Reeve (2009: 299) juga mengakui bahawa emosi ialah fenomena sosial. Apabila seseorang individu berada dalam keadaan beremosi, maka individu itu akan menghantar isyarat melalui wajah, postur badan dan suara yang menghubungkan kualiti dan emosi yang mendalam kepada orang lain.

Sehubungan itu, gambaran emosi manusia dapat diperlihatkan menerusi kesusasteraan. Hal ini dibuktikan menerusi penghasilan karya atau naskhah berbentuk puisi dan prosa yang digarap dengan kepelbagaian elemen emosi. Pengarang mengolah dan mengeksplotasi emosi dan perasaan yang diperlihatkan menerusi jalan cerita atau watak-watak dalam kesusasteraan tersebut. Menurut Johnson-Laird \& Oatley (2010: 110) pengarang mampu untuk mendorong khalayak untuk merasai emosi dalam diri watak yang dipersembahkan menerusi karya yang dihasilkan.

Oleh sebab itulah, pemaparan elemen emosi dalam kesusasteraan menjadi salah satu fokus dan tumpuan kepada sesebuah penceritaan. Menurut Ali dan Siti Hajar (2005:22) kesusasteraan biasanya dikaitkan dengan penampilan melalui bahasa akan perasaan-perasaan yang sering kali berisikan emosi yang berbagai rupa seperti suka, duka dan semangat. Selain itu, emosi juga merupakan unsur pembantu yang digarap bersama bagi menjadikan karya berkesan. Kedudukan emosi dalam kesusasteraan dapat dianggap sebagai sesuatu manisan atau rempah ratus yang mengenakkan makanan jiwa (Ali \& Siti Hajar, 2005:22).

Elemen emosi dalam kesusasteraan dapat ditelusuri dari pelbagai bentuk seperti lontaran dialog dan ekspresi watak serta paparan struktur cerita. Menurut 
Ismail (2008: 1) karya sastera bercorak prosa mampu untuk menawan hati dan dapat menyentuh perasaan audiens seperti terharu, sedih, ngeri, gembira dan suspen. Hal ini turut diakui oleh Oatley (2006: 400) yang menjelaskan bahawa dalam cerita bertulis atau prosa lazimnya memperlihatkan emosi dan kesan emosi pada klimaks penceritaan. Hal ini kerana penceritaan tersebut menyelitkan puisi, cerita fiksyen dan cerita rakyat yang membawa kepada unsur emosi.

Oleh itu, kajian ini akan membincangkan pemaparan elemen emosi dalam teks Hikayat Putera Jayapati dan Hikayat Si Miskin khususnya dari sudut bentuk kinesik yang berperanan sebagai komunikasi bukan lisan watak dalam kedua-dua teks yang dipilih.

\section{SINOPSIS RINGKAS HIKAYAT PUTERA JAYAPATI DAN HIKAYAT SI MISKIN}

Kajian ini menggunakan dua buah teks, iaitu Hikayat Putera Jayapati yang diselenggara oleh Wahyunah (2004) dan Hikayat Si Miskin yang diselenggara oleh Abu Bakar (2016). Hikayat Putera Jayapati mengisahkan seorang raja bernama Raja Kala Mandu yang merupakan pemerintah negeri Langgam Jaya. Diceritakan bahawa Raja Kala Mandu merupakan seorang raja yang pemurah dan adil. Namun begitu, Raja Kala Mandu dan permaisuri masih belum dikurniai cahaya mata. Suatu hari, baginda diberitahu oleh ahli nujum bahawa baginda akan dikurniakan seorang putera yang masyhur maka, saban hari baginda memohon doa agar dikurniakan anak. Tidak lama kemudian, permaisuri hamil dan lahirlah seorang putera lelaki yang diberi nama Putera Jayapati. Selepas kelahiran Putera Jayapati, ahli nujum telah mempersembahkan ramalannya mengenai fitnah yang akan menimpa Putera Jayapati, iaitu fitnah daripada binatang empat kaki. Keadaan tersebut telah menimbulkan kegusaran dalam diri baginda dan permaisuri.

Pada suatu hari, ketika Putera Jayapati bermain bersama-sama budak-budak yang lain di padang, maka turunlah seorang jin yang berubah menjadi kuda emas. Kuda emas tersebut melarikan Putera Jayapati. Maka gemparlah seluruh negeri Langgam Jaya apabila Putera Jayapati dilarikan kuda emas ke dalam hutan. Keadaan tersebut telah menyebabkan baginda dan permaisuri meratap dan menangisi kehilangan Putera Jayapati apabila menteri dan hulubalang tidak menemui jejak kuda emas itu. Maka, Putera Jayapati pun terjatuh dari atas kuda emas itu dan menuju ke sebuah gunung. Di sana Putera Jayapati telah menemui Bakawan Narada yang mengajarkan pelbagai ilmu kesaktian 
dalam berperang menewaskan raksasa, geroda dan jin serta mampu untuk menurunkan hujan, api, batu, hujan senjata dan beberapa hikmat yang lain.

Setelah itu, Putera Jayapati meneruskan perjalanannya dan bertemu dengan Malik Indera. Malik Indera memiliki seorang anak lelaki bernama Indera Samudera Lela dan seorang anak perempuan bernama Puteri Indera Nurlaila yang sudah bertunang dengan anak raja peri bernama Raja Indera Wiruna. Putera Jayapati telah jatuh cinta dengan Puteri Indera Nurlaila dan menyebabkan berlakunya peperangan. Akhirnya, Putera Jayapati berjaya menewaskan Raja Indera Wiruna. Putera Jayapati berkahwin dengan Puteri Indera Nurlaila dan kembali semula ke negeri Langgam Jaya dan menjadi pemerintah yang pemurah dan adil serta dikasihi rakyatnya.

Hikayat Si Miskin pula mengisahkan tentang Si Miskin dan isteri yang hidup melarat. Jika Si Miskin pergi ke pasar, dia akan diusir dan dilemparkan orang dengan batu dan kayu sehingga menyebabkan badannya bengkak dan berdarah. Si Miskin yang kelaparan mencari makan ditimbunan sampah untuk mengalas perutnya. Mereka dikurniakan anak lelaki bernama Marakarmah. Pada suatu hari, secara tiba-tiba Si Miskin menjadi kaya raya setelah menemui tajau atau tempayan yang berisi emas. Maka, Si Miskin bergelar Maharaja Indera Angkasa dan isterinya bernama Tuan Puteri Ratna Dewi serta negerinya pula dinamakan sebagai Puspa Sari. Tidak lama kemudian, Tuan Puteri Ratna Dewi hamil dan melahirkan seorang anak perempuan bernama Tuan Puteri Nila Kesuma. Kemasyhuran yang dimiliki Maharaja Indera Angkasa telah menyebabkan ramai yang cemburu dan dengki sehingga timbulnya fitnah mengenai kedua-dua anakanda baginda yang dikatakan akan menyebabkan kecelakaan kepada kerajaan baginda. Keadaan ini menyebabkan baginda hilang pertimbangan dan bertindak menghalau kedua-dua anakanda baginda. Tidak lama kemudian, negeri Puspa Sari terbakar dan baginda serta isteri kehilangan segala-galanya dalam sekelip mata. Maka, bermulalah perjalanan mereka dua beradik. Sepanjang perjalanan tersebut banyak ujian dan halangan yang ditempuhi terutamanya dalam mendapatkan bekalan makanan. Suatu hari, Marakarmah dan Tuan Puteri Nila Kesuma terpisah ketika Marakarmah ingin mencari kayu api untuk membakar burung yang ditangkapnya sebagai juadah mereka. Malangnya, Marakarmah telah dipukul dan dibuangkan ke dalam laut kerana dituduh mencuri. Keadaan tersebut telah menyebabkan Tuan Puteri Nila Kesuma tinggal sendirian di dalam hutan dan telah diselamatkan oleh Raja Mengindera Sari. Kemudian Tuan Puteri Nila Kesuma dinamakan sebagai Tuan Puteri Mayang Mengurai.

Setelah Marakarmah menghadapi pelbagai rintangan dan dugaan sepanjang pengembaraannya itu, pada akhirnya Marakarmah bertemu semula 
dengan ayahanda dan bondanya serta adindanya, Tuan Puteri Nila Kesuma. Diceritakan juga diakhirnya Maharaja Marakarmah berkahwin dengan Tuan Puteri Cahaya Khairani dan menjadi raja pemerintah di negeri Mercu Indera. Setiap tahun segala raja-raja akan menghantar utusan, membawa bingkisan dan menghadap Maharaja Marakarmah.

\section{KONSEP KOMUNIKASI EMOSI}

Luahan emosi manusia dapat diperlihatkan menerusi ekspresi atau tingkah lakunya sebagai salah satu komunikasi antara diri individu dengan individu atau kelompok yang lain. Menurut M. Darwis Hude (2006: 248) emosi yang dialami manusia tidaklah dirasakan sendiri, tapi dikomunikasikan pula kepada pihak lain, baik langsung mahupun tidak langsung, dan dikehendaki atau tidak dikehendaki. Ada ketikanya manusia kecewa, sedih atau cemas, tapi pada saat yang lain merasakan kegembiraan dan kepuasan. Lalu emosi-emosi itu diespresikan dengan berbagai-bagai cara sebagai bentuk komunikasi pada diri sendiri dan juga orang lain.

Dalam hal ini, M. Darwis Hude (2006:248-249) juga menjelaskan bahawa emosi yang terjadi dalam kehidupan sehari-hari berfungsi sebagai pembangkit dan pendorong semangat untuk melakukan tindakan yang diperlukan dalam rangka mempertahankan ego dan kelestarian hidup. Emosi juga menjadi instrumen untuk mengetahui hal-hal yang dicapai dalam hidup. Komunikasi emosi membawa pesanan kepada diri sendiri terhadap perkara yang dialami dan juga kepada kelompok sosial. Setiap emosi yang dialami akan mengirimkan maklumat mengenai perkara yang dialami ketika itu dan tubuh manusia akan memberikan isyarat komunikasi sebagai tindak balas kepada emosi yang dialaminya. Selain itu, ketika seseorang individu berkomunikasi melalui emosi dengan individu atau kelompok lain, secara tidak langsung akan mendorong individu atau kelompok lain turut sama merasai emosi tersebut. Perkara ini disebut sebagai pertama; ketularan emosi (emotional contagion), iaitu seseorang individu menangkap emosi tertentu daripada ekspresi emosi yang sedang dialami orang lain. Kedua; empati iaitu individu melibatkan diri seolah-olah mengalami sendiri emosi yang dialami oleh individu lain. Hal ini bermaksud ketularan emosi dan empati merupakan suatu bentuk komunikasi emosi antara seorang individu dengan individu lain (M. Darwis Hude, 2006: 253-254). 


\section{KOMUNIKASI EMOSI DALAM KESUSASTERAAN DAN KESENIAN}

Kebiasaannya, elemen emosi menjadi medium komunikasi yang menghubungkan pengarang dengan khalayak. Hal ini dapat ditelusuri melalui penerapan elemen emosi oleh pengarang terhadap pembinaan watak-watak dalam karya novel. Menurut Chen dan Mawar (2017) pengarang wanita lebih banyak mengajukan tema cinta dengan menampilkan watak wanita sebagai watak protagonis dalam karya novel yang dihasilkan. Kajian mereka lebih menumpukan perbandingan cinta sebagai wadah komunikasi emosi wanita dalam novel Love in a Fallen City oleh Eileen Chang dan novel Jalur Sinar di Celah Daun oleh Zaharah Nawawi menggunakan Teori Tiga Segi Cinta oleh Sternberg. Kedua-dua novel tersebut menampilkan komunikasi emosi cinta yang berbeza. Novel Love in a Fallen City menampilkan watak wanita, Liasu yang berkahwin dengan Liuyun atas dasar nafsu cinta sehingga menyebabkan hubungan berakhir dengan cinta kosong dan bertukar tragedi. Namun begitu, berbeza dengan watak Tijah dalam novel Jalur Sinar di Celah Daun yang menampilkan emosi cinta watak Tijah dan Dali yang penuh unsur keintiman, nafsu dan komitmen. Malah, hubungan cinta mereka menggambarkan cinta yang sempurna.

Selain itu, Maznida dan Tengku Intan Marlina (2018) pula lebih menumpukan emosi protagonis watak lelaki. Mereka menyatakan bahawa emosi merupakan mekanisme untuk luahan komunikasi dan perasaan seseorang individu. Emosi lahir daripada perasaan jiwa yang sangat kuat, yang boleh ditonjolkan melalui tindak balas tingkah laku seseorang secara psikologi, biologi dan melalui respons mental seseorang. Kajian diperlihatkan menerusi perbandingan bentuk-bentuk emosi yang mempengaruhi watak protagonis lelaki dalam novel Penyeberang Sempadan oleh Anwar Ridhwan (2012) dan novel Kafta on The Shore oleh Haruki Murakami (2005) menggunakan Teori Kecerdasan Emosi Goleman. Penelitian emosi terhadap kedua-dua novel ini diteliti dari sudut bait kata-kata, frasa, ayat, dialog atau perenggan yang menujukkan wujudnya bentuk emosi yang dialami oleh watak protagonis lelaki. Pemaparan bentuk emosi yang dominan dalam novel Penyeberang Sempadan ialah emosi benci, sedih dan marah, manakala dalam novel Kafka on The Shore pula memperlihatkan bentuk emosi takut, sedih dan keseronokan yang paling dominan. Secara keseluruhan, kedua-dua novel tersebut menunjukkan persamaaan yang seimbang apabila emosi sedih dikesan mendominasi hampir kedua-dua novel. 
Kajian komunikasi emosi tidak hanya diperlihatkan dalam novel, namun turut diperhalusi menerusi pertunjukan silap mata klasik. Dalam hal ini, Intan Putri (2018) telah meneliti komunikasi non verbal ahli silap mata dalam pertunjukan silap mata klasik. Menurut beliau, komunikasi non verbal dapat mengungkapkan hal-hal seperti emosi yang tidak dapat ditafsirkan melalui komunikasi verbal. Silap mata klasik lebih dominan dengan mengutamakan bahasa tubuh (kinesik) dalam setiap pertunjukannya. Hal ini kerana bahasa tubuh atau kinesik dalam pertujukan silap mata bentuk komunikasi ataupun interaksi yang dilakukan antara ahli silap mata dan penonton. Pertujukan silap mata merupakan media untuk ahli silap mata menyampaikan pesan atau maklumat kepada penonton. Kajian tersebut mendapati bahawa antara tiga komponen utama dalam komunikasi non verbal yang ditampilkan ialah riak muka, gerak isyarat dan postur. Antara ekspresi wajah yang paling dominan ditampilkan oleh Ray Antylogic dalam pertunjukan silap mata ialah ekspresi bahagia, terkejut, sedih, dan senyuman seperti senyum simpul, senyum biasa dan senyum lebar. Ahli silap mata akan menyampaikan pesanan kinesik kepada penonton ketika pertunjukan silap mata yang meminimumkan dialog dan memerlukan interpretasi yang mendalam terhadap gerakan tubuh yang ditampilkannya untuk difahami oleh penonton.

Oleh yang demikian, berdasarkan kajian terdahulu didapati bahawa manusia berkomunikasi antara satu sama lain melalui elemen emosi yang diperlihatkan dalam karya novel dan seni silap mata seperti yang dilakukan oleh Chen dan Mawar (2017), Maznida dan Tengku Intan Marlina (2018) serta Intan Putri (2018). Namun begitu, terdapat beberapa kajian yang menyentuh tentang jenis-jenis emosi dalam kesusasteraan seperti Nurul Afifah Adila dan Normaliza (2016) yang memperlihatkan ekspresi emosi dalam sajak. Berdasarkan kajian tersebut terdapat beberapa ekspresi emosi seperti cinta, kecewa, marah, gembira dan sedih yang ditemui dalam sajak yang dikaji. Mereka turut menyatakan bahawa emosi memainkan peranan utama dalam memeriahkan sajak. Kehadiran emosi dapat meningkatkan minat pembaca terhadap puisi moden. Hal ini kerana, emosi yang diluahkan dalam sajak dapat membantu pembaca dalam membentuk identiti dan pemikiran mereka.

Kajian Nurul Afifah Adila dan Normaliza (2016) memperlihatkan persamaan kajian oleh Normaliza, Siti Nur Aliaa dan Nur Maisarah (2017) yang meneliti konflik emosi menerusi lirik lagu. Kajian tersebut telah menemui beberapa konflik emosi seperti emosi sedih, marah, gembira dan gembira yang dilakukan terhadap 20 subjek lelaki dan perempuan daripada beberapa buah kelas di sebuah sekolah di Selangor. Menurut Normaliza et al. (2017) lagi kajian tersebut memberikan manfaat kepada penulis lirik dan pelajar 
sekolah kerana penulis lirik akan mendapat gambaran mengenai perasaan pendengar lagu untuk menulis lirik lagu yang lebih berkesan.

Selain kajian emosi terhadap sajak dan lirik lagu, turut diperlihatkan kajian emosi terhadap teks tradisional seperti yang dilakukan oleh Afidatul Syazwani, Norazimah dan Abdul Halim (2020). Kajian tersebut menumpukan pada magis dan aspek kelegaan jiwa berdasarkan perspektif emosi hairan dalam Hikayat Marakarmah. Kajian ini menggunakan salah satu prinsip yang terdapat dalam Teori Rasa-Fenomenologi, iaitu emosi hairan. Pengukuran kesan emosi hairan bersandarkan struktur ayat dan gaya bahasa yang digunakan pengarang dalam teks ini. Kelegaan jiwa kepada khalayak ini hadir apabila khalayak menikmati karya sebagai "objek estetik" dan proses pembacaan dan transformasi emosi yang berlaku sebagai "pengalaman estetik". Berdasarkan penelitian didapati bahawa terdapat 12 peristiwa yang melibatkan emosi hairan dan enam peristiwa melibatkan gaya bahasa suspens, dua peristiwa melibatkan gaya bahasa dialog, dua peristiwa melibatkan gaya bahasa personafikasi dan dua peristiwa melibatkan gaya bahasa hiperbola. Secara keseluruhannya gaya bahasa suspens mendominasi peristiwa berbanding gaya bahasa yang lain dan berhasil menerbitkan kesan emosi hairan khalayak. Mereka juga turut berpendapat bahawa karya ialah medium penyembuhan yang terbaik apabila watak-watak di dalam karya serta emosinya disebatikan dengan perwatakan dan emosi khalayak.

Oleh yang demikian, menerusi kajian lepas memperlihatkan kajian yang pelbagai dari sudut elemen emosi dan komunikasi emosi. Namun begitu, kajian emosi sebagai komunikasi bukan lisan tidak menampakkan kajian yang mendalam dan menyeluruh. Oleh itu, kelompongan kajian lepas telah mendorong untuk menghasilkan satu kajian baharu mengenai paparan elemen emosi berbentuk kinesik sebagai komunikasi bukan lisan watak dalam naskhah Melayu seperti Hikayat Putera Jayapati dan Hikayat Si Miskin.

\section{KOMUNIKASI BUKAN LISAN DALAM MEMERIHALKAN EMOSI}

Mohd Baharudin dan Mohd Khairie (2015: 58-59) menjelaskan komunikasi bukan lisan dikenali juga sebagai komunikasi tanpa perkataan dan merupakan satu bentuk komunikasi yang penting. Komunikasi bukan emosi boleh mentafsirkan emosi, personaliti, tujuan dan juga status sosial seseorang. Di samping itu, komunikasi bukan lisan juga dapat meningkatkan keberkesanan penyampaian sesuatu mesej serta berfungsi sebagai pelengkap kepada komunikasi lisan. 
Komunikasi lisan wujud tanpa disedari oleh manusia. Gerakan anggota badan adalah di luar kawalan semasa berkomunikasi kerana pergerakan bukan lisan berlaku secara spontan. Individu boleh melihat individu lain sama ada sedang bergembira, sedih, tergesa-gesa melalui mimik muka dan paralinguistik tanpa perlu individu itu memberitahu secara lisan. Komunikasi lisan juga lebih baik dan berkesan untuk digunakan bagi menunjukkan perasaan dan idea. Ini boleh dibuktikan dengan mimik muka sedih, senyum ketika gembira, pergerakan tangan kita berucap, dan nada suara yang boleh menyakinkan penonton. Selain itu, komunikasi bukan lisan sukar ditafsirkan secara tepat. Hal ini kerana pentafsiran mesej sukar dilakukan dengan jelas yang memerlukan pertimbangan semasa membuat penafsiran. Antara faktor-faktornya ialah konteks, sejarah perhubungan antara pengirim dengan penerima mesej dan budaya (Mohd Baharudin \& Mohd Khairie, 2015: 59-60).

Dalam hal ini, Abdul Mua'ti@ Zamri (2016: 50-51) menjelaskan bahawa sumber maklumat yang paling penting untuk membuat pertimbangan tanggapan sosial adalah melalui perlakuan bukan verbal manusia khususnya ekspresi muka, pergerakan tubuh, nada suara dan unsur-unsur lain dalam komunikasi verbal dan bukan verbal. Proses pembentukan tanggapan sosial berdasarkan tingkah laku adalah dengan melihat aksi dan reaksi seseorang ketika berkomunikasi sama ada verbal atau bukan verbal. Pertimbangan tersebut dilihat melalui eskpresi muka, pakaian dan bahasa badan. Menurut Mohd Baharudin dan Mohd Khairie (2015: 61) komunikasi bukan lisan juga dirujuk sebagai metakomunikasi, iaitu bentuk komunikasi yang mampu menyampaikan pelbagai makna dan mempunyai makna yang berbeza-beza bergantung pada persepsi seseorang.

\section{TEORI KOGNITIF ARNOLD-ELLIS}

Mahmood Nazar (2018: 320) menjelaskan Teori Kognitif Arnold-Ellis menekankan kepentingan terhadap penilaian serta interpretasi sesuatu peristiwa daripada rangsangan yang menyebabkan terhasilnya emosi. Arnold dan Ellis dalam Mahmood Nazar (2018: 320) menyatakan bahawa manusia menginterpretasi pelbagai situasi dan peristiwa yang berkaitan sebelum memaparkan sesuatu emosi. Oleh itu, rangsangan luaran diterima oleh talamus dan terus dihantar ke bahagian korteks untuk dianalisis dan diinterpretasi. Kemudiannya rangsangan itu dihantar ke bahagian hipotalamus yang bertanggungjawab menghasilkan reaksi emosi yang bersesuaian.

Elemen yang terkandung dalam teori ini dapat diperlihatkan menerusi Rajah 1 yang berikut: 


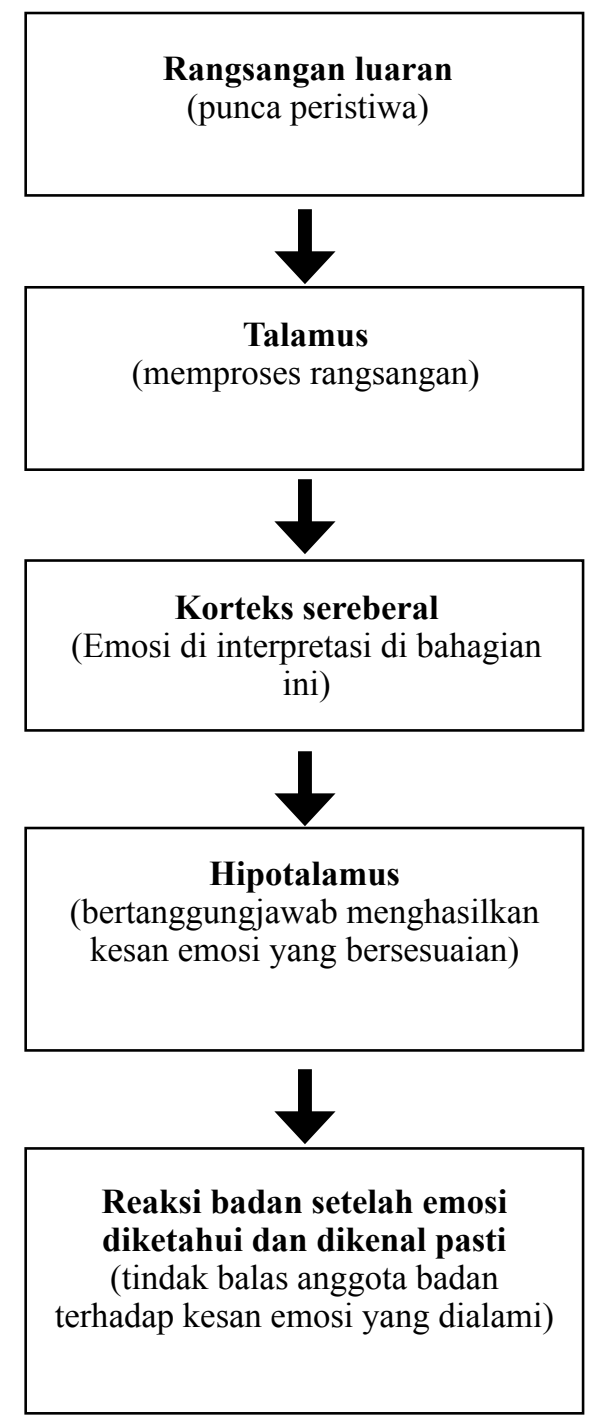

Rajah 1 Diubah suai daripada Teori Emosi Kognitif Arnold-Ellis (Sumber: Mahmood Nazar, 2018: 320) 


\section{HIKAYAT PUTERA JAYAPATI DAN HIKAYAT SI MISKIN}

Kesusasteraan memperlihatkan kepelbagaian hasil karya yang mengandungi elemen emosi termasuklah dalam naskhah Melayu. Lazimnya, pengarang yang menghasilkan sesebuah karya tidak hanya menyampaikan maklumat dan pemikiran tetapi juga menyalurkan emosinya melalui penciptaan watakwataknya. Lantaran itu, dalam naskhah Melayu tradisional ini memperlihatkan watak yang mengekspresikan emosi mereka berbentuk kinesik khususnya sebagai salah satu cara berkomunikasi antara mereka.

Menurut Mohd Baharudin dan Mohd Khairie (2015: 66) kinesik merujuk anggota badan manusia semasa berkomunikasi. Dalam konteks komunikasi, kinesik amat penting untuk menggambarkan emosi, kemesraan, tingkah laku dan hubungan antara individu. Kinesik diklasifikasikan kepada beberapa bentuk, iaitu isyarat mata, gerakan badan dan tangan, mimik muka dan sentuhan. Namun begitu, dalam konteks kajian ini, tumpuan tidak hanya pada bentuk kinesik seperti isyarat mata, wajah, sentuhan, dan gerakan anggota badan malah turut dilihatcmenerusi tingkah laku luar kawalan yang dipaparkan menerusi naskhah Melayu tradisional yang dikaji, iaitu Hikayat Putera Jayapati dan Hikayat Si Miskin.

\section{Bentuk Kinesik Melalui Isyarat Mata}

Emosi manusia dapat diperlihatkan atau dikongsi melalui saluran komunikasi mata. Menurut Mohd Baharudin dan Mohd Khairie (2015: 67) komunikasi mata berfungsi untuk menggambarkan minat, emosi, perhatian, kegembiraan, marah dan terancam. Jelingan, renungan tajam, kelayuan mata serta kelipan mata dapat memberikan mesej tertentu semasa berkomunikasi. Malah melalui gerakan mata juga dapat memperlihatkan peribadi seseorang sama ada bersifat pemalu, bersedih, manja atau menunjukkan minat terhadap interaksi yang sedang berlaku. Pada amnya, hubungan mata secara renungan menandakan perasaan yang positif seperti gemar, suka, dan tertarik hati. Walau bagaimanapun, apabila renungan itu terlalu panjang dan lama, maka ekspresi emosi sudah berubah dan berlainan. Kepelbagaian bentuk renungan dan elakan pandangan mata dapat memberitahu perasaan dan emosi yang dialami oleh seseorang (Mahmood Nazar, 2018: 326).

Naskhah Melayu banyak memerihalkan perkara berkaitan komunikasi emosi watak terutamanya dalam mengekspresikan emosi sedih. Dalam konteks kajian ini, komunikasi berbentuk kinesik melalui isyarat mata dapat diperlihatkan menerusi perbuatan mengalirkan air mata atau menangis. Menurut M. Darwis Hude (2006: 180), tindakan menangis merupakan 
perbuatan mengeluarkan air mata. Namun begitu, tangisan tidak semestinya mencerminkan kesedihan tetapi juga dapat ditafsirkan sebagai gembira, terharu mahupun pura-pura. Hal ini dapat dilihat melalui watak dalam naskhah Melayu tradisional yang berkomunikasi melalui isyarat mata dalam mengekspresikan emosi yang dialami. Perhatikan teks Hikayat Putera Jayapati yang memerihalkan keadaan ini:

Maka segala budak-budak yang banyak itu pun kesemuanya pun habislah tercengang-cengang melihat kelakuan kuda itu melarikan Putera Jayapati. Maka sekaliannya budak-budak itu pun berlari-lari / kembali serta dengan tangisnya. Setelah sampai, maka baginda pun terkejut daripada beradu itu. Maka dilihatnya oleh baginda akan budak-budak itu berlari-lari serta tangis.

Maka baginda pun melihat kepada anakanda baginda kepada tepat duduk itu sudah tiada. Maka baginda pun berdebar-debar rasa hatinya, maka titah baginda, "Hai budak-budak, mengapa maka engkau sekalian ini teriyak?" Maka kata budak-budak itu, "Ya tuanku, akan paduka anakanda itu sudah dilarikan oleh kuda emas pergi ke dalam hutan berserta dia tuanku." (Hikayat Putera Jayapati, 2004:8)

Petikan ini memerihalkan komunikasi emosi antara watak budak-budak dengan Raja Kala Wandu. Komunikasi tersebut diperlihatkan melalui isyarat mata, iaitu mengalirkan air mata atau perilaku tangis atau teriak. Komunikasi emosi ini bertujuan untuk memberitahu kepada individu lain mengenai perasaan yang dialami ketika itu. Ketika budak-budak sedang bermain bersama-sama anakanda Raja Kala Wandu, iaitu Putera Jayapati, tidak lama kemudian Putera Jayapati telah dilarikan oleh kuda emas. Keadaan tersebut telah menyebabkan budak-budak itu terkejut sehingga menyebabkan mereka menangis kerana ketakutan akibat kehilangan Putera Jayapati. Malah, mereka juga takut jika dimarahi Raja Kala Wandu dan dalam masa yang sama bimbang akan keadaan Putera Jayapati. Tangisan dan teriakan mereka itu kemudiannya telah didengari Raja Kala Wandu, iaitu ayahanda Putera Jayapati. Menurut Ramli (1990: 11), apabila manusia dilanda bimbang akan menimbulkan perasaan yang tidak menyenangkan kerana takut berlakunya perkara yang buruk terhadap diri sendiri atau orang lain seperti yang digambarkan menerusi watak budak-budak itu. Perkara ini seiring dengan Teori Kognitif Arnold Ellis yang membuktikan bahawa peristiwa ketakutan akibat kehilangan Putera Jayapati telah menyebabkan terbentuknya emosi sedih budak-budak yang diperlihatkan menerusi isyarat mata iaitu perilaku teriak dan tangis. Jelaslah bahawa wujudnya komunikasi 
emosi berbentuk kinesik melalui isyarat mata, iaitu tangis dan teriak yang mengeluarkan air mata.

Selain itu, terdapat juga komunikasi emosi antara watak Puteri Indera Nurlaila dengan Putera Jayapati. Komunikasi emosi melalui isyarat mata dipertontonkan melalui perilaku tuan puteri yang menangis seperti yang digambarkan dalam petikan teks berikut:

Setelah sudah berkata-kata itu, maka Putera Jayapati pun turunlah berjalan naik ke ma(h)ligai tuan puteri itu. Adapun pada ketika itu tuan puteri pun duduk menangis serta diadap segala dayang-dayang biti perwara sekalian. Hatta maka Putera Jayapati pun datang seraya berkata, "Mengapa tuan adinda ini menangis? Sayangkah tuan akan Raja Indera Wiruna itu mati sebab tuan duduk menangis ini. Jika kekanda tahu, tiadalah kekanda bunuh dia." Maka tuan puteri pun terkejut lalu tunduk dengan malunya, berdiam dirinya seraya menyapu air matanya. Maka dimaniskan mukanya itu seraya memandang kepada Putera Jayapati seraya katanya, "Gilakah beta tangiskan anak raja itu. Yang beta tangiskan ini kerana kekanda datang lambat, maka sebab itulah maka beta menangis ini kerana tiada selesai peperangan kekanda dengan anak raja itu. Siapa tahu pekerjaan perang itu bak dan jahat itu sama keduanya kerana beta ini perempuan, tiada ke mana sampainya...”(Hikayat Putera Jayapati, 2004:63)

Penelitian terhadap petikan teks ini jelas menampakkan berlakunya proses komunikasi emosi antara watak tuan puteri dengan Putera Jayapati melalui perilaku menangis. Perilaku menangis merupakan reaksi atau tindak balas kepada perasaan yang dialami. Keadaan tersebut berlaku kerana tuan puteri yang bimbang akan keadaan Putera Jayapati yang masih belum pulang daripada peperangan sehingga menyebabkan watak tuan puteri mengalirkan air matanya. Menurut al-Awaisyah (2009: 7), seseorang individu yang menangis kerana khuatir adalah disebabkan tindak balas terhadap sesuatu peristiwa yang menyakitkan. Berdasarkan Teori Kognitif Arnold-Ellis, amat jelas sekali rangsangan luar, iaitu peristiwa Putera Jayapati yang pulang lewat pulang daripada peperangan telah menyebabkan berlakunya proses emosi kebimbangan tuan puteri. Emosi yang terbentuk telah menghasilkan perilaku menangis merupakan isyarat mata sebagai respons kepada emosi yang dialami tuan puteri. Dalam hal ini, dapat membuktikan bahawa emosi tuan puteri diekspresikan melalui isyarat mata sebagai salah satu cara komunikasinya dengan Putera Jayapati untuk meluahkan emosi bimbangnya itu. Kajian ini juga turut memperlihatkan komunikasi emosi menerusi naskhah Melayu Hikayat Si Miskin, seperti contoh petikan yang berikut: 
Setelah pagi-pagi hari, maka berkatalah Si Miskin kepada isterinya, "Ya tuan, matilah rasaku ini, sangatlah sakit rasanya tubuhku ini, maka tiadalah berdaya lagi, hancurlah rasanya angotaku ini." Maka, ia pun tersedu-sedu menangis. Maka, terlalu belas rasa hati isterinya melihat laku suaminya demikian itu. Maka, ia pun menangis pula seraya mengambil daun kayu lalu dimamahnya. Maka, disapukannyalah seluruh tubuh suaminya sambil ia berkata, "Diamlah tuan, jangan menangis, sudahlah dengan untungnya kita, maka jadi selaku ini.” (Hikayat Si Miskin, 2016:3)

Berdasarkan petikan teks ini menunjukkan wujudnya komunikasi emosi antara watak Si Miskin dan isterinya yang diperlihatkan menerusi isyarat mata, iaitu reaksi menangis. Pada asalnya, Si Miskin merupakan raja keinderaan yang telah disumpah dibuang ke alam dunia sehingga menyebabkan Si Miskin terpaksa menjalani kehidupan yang sulit dan sukar. Keadaan ini juga telah mengakibatkan Si Miskin perlu mencari makanan di hutan untuk meneruskan kehidupan bersama-sama isterinya. Pemerhatian dalam situasi yang dialami oleh kedua-dua watak menunjukkan bahawa $\mathrm{Si}$ Miskin mengalami kemalangan sehingga badannya luka dan berdarah ketika masuk ke hutan ketika mencari makanan untuk isterinya. Kesukaran hidup yang dilalui menyebabkan emosinya terganggu sehingga mengalirkan air mata. Isyarat mata menangis yang dipamerkan oleh Si Miskin turut dirasai oleh isterinya yang begitu bersimpati dan kasihan dengan keadaan suaminya sehingga dia turut sama menangis. Hal ini amat bertepatan dengan Teori KognitifAlbert-Ellis yang menegaskan bahawa rangsangan luar, iaitu peristiwa kesusahan dan kesukaran dalam menjalani kehidupan telah menyebabkan terbentuknya emosi sedih yang diperlihatkan menerusi isyarat mata seperti menangis. Perilaku ini jelas menunjukkan tindak balas kepada emosi yang dialami oleh kedua-dua watak.

Lantaran itu, komunikasi emosi yang wujud antara mereka membuktikan bahawa adanya hubungan interpersonal. Hubungan interpersonal merupakan ikatan yang kuat antara seorang individu dengan individu lain atau lebih. Daya penarik antara individu tersebut membawa kepada hubungan dan ikatan yang erat serta pada akhirnya membentuk hubungan interpersonal yang kuat. Menurut M. Darwis Hude (2006: 184), manusia sebagai makhluk sosial sentiasa memerlukan interaksi lingkungan sosialnya. Interaksiinteraksi itu kemudian memantulkan komunikasi secara verbal mahupun non-verbal, secara langsung ataupun tidak langsung. Dalam al-Quran juga turut dinyatakan bahawa hubungan interpersonal memungkinkan munculnya 
tingkah laku yang menimbulkan kesedihan (M. Darwis Hude, 2006: 184). Hubungan interpersonal yang wujud antara kedua-dua watak ini juga untuk mendapatkan persetujuan dalam penyelesaian konflik emosi yang dialami oleh Si Miskin. Pada masa yang sama, watak Si Miskin yang menangis itu juga berusaha untuk memujuk isterinya agar memahami keadaan $\mathrm{Si}$ Miskin yang berada dalam kesukaran. Lantaran itu, keadaan tersebut telah mendorong isterinya untuk menjamah daun kayu demi kelangsungan hidup. Hal ini seperti yang ditegaskan oleh Salmah Jan (2018: 49) bahawa tujuan komunikasi interpersonal adalah untuk menjelaskan isu-isu tertentu atau mencapai kesepakatan dalam penyelesaian masalah yang timbul secara bersemuka. Malah, Abdul Mua'ti @ Zambri (2016: 54) juga memberikan pandangannya bahawa komunikasi interpersonal merupakan usaha untuk memujuk atau mempengaruhi orang lain. Jelaslah bahawa wujud hubungan interpersonal yang diperlihatkan menerusi watak Si Miskin dan isterinya dalam berkomunikasi secara bukan lisan melalui isyarat mata.

Selain itu, terdapat juga peristiwa yang berlaku antara watak Tuan Puteri Nila Kesuma dan Marakarmah yang mengekspresikan emosi mereka melalui isyarat mata sebagai komunikasi bukan lisan. Perhatikan petikan teks ini:

Alkisah, maka tersebutlah perkataan Marakarmah berjalan dua bersaudara itu. Maka Tuan Puteri Nila Kesuma itu pun menangis hendak minum susu. Maka Marakarmah pun menangis seraya berkata, "Diamlah adinda, jangan menangis kerana kita orang celaka. Di manakah kita boleh mendapat susu lagi? Kita sudah dibuangkan orang. Maka, diberinyalah kepada adiknya ketupat itu sebelah. Maka, dimakannyalah. Maka, ia pun diamlah.” (Hikayat Si Miskin, 2016: 16)

Penelitian terhadap petikan teks ini membuktikan bahawa wujudnya komunikasi emosi melalui isyarat mata antara watak Tuan Puteri Nila Kesuma dan Marakarmah. Komunikasi bukan lisan itu diperlihatkan menerusi perilaku tuan puteri yang menangis kerana kelaparan mahukan susu. Berdasarkan Teori Kognitif Albert-Ellis jelas menekankan rangsangan luaran membentuk emosi yang diperlihatkan menerusi perilaku seseorang. Keadaan ini dibuktikan melalui watak tuan puteri yang berhadapan dengan peristiwa kelaparan. Akibat rasa lapar itu, berlakunya proses rangsangan luar yang membawa kepada terbentuknya emosi sedih yang jelas kelihatan menerusi isyarat mata, iaitu perilaku menangis.

Sehubungan itu, emosi yang membelenggu tuan puteri itu juga dirasai Marakarmah yang turut sama menangis. Keadaan ini berlaku disebabkan 
timbulnya rasa empati dalam diri Marakarmah yang turut merasai emosi saudaranya itu. Malah, Marakarmah memujuk tuan puteri dengan menghulurkan ketupat sebagai gantinya. Seseorang individu yang memiliki sifat empati dalam diri bukan sahaja berasa belas dan bersimpati kepada orang lain tetapi, turut sama-sama menyelami dan merasai perasaan seperti yang diperlihatkan melalui watak Marakarmah. Dalam hal ini, Meydian dan Endang Sri Indrawati (2018: 144) menjelaskan bahawa empati merupakan sifat individu dalam meletakkan dirinya dalam keadaan orang lain. Dalam erti kata lain, kemampuan individu untuk memahami sesuatu yang sedang difikirkan dan dirasakan individu lain terhadap situasi yang sedang dialami oleh individu itu.

\section{Bentuk Kinesik melalui Wajah}

Seorang individu juga dapat meluahkan emosinya melalui wajah atau mimik muka sebagai salah satu cara untuk berkomunikasi dengan individu lain. Menurut M. Darwis Hude (2006: 47) ekspresi wajah merupakan ekspresi paling umum untuk menunjukkan seseorang sedang mengalami peristiwa emosi. Wajah murung, merah, mengerut atau pucat ialah bentuk ekspresi emosi yang lazim dialami. Manusia mengkomunikasikan emosi-emosi dasar dengan ekspresi yang sama dan sangat mudah dikenal pasti dari eskpresi wajah. Selain itu, Jalaludin dalam Mohd Baharudin dan Mohd Khairie (2015: 67) menjelaskan bahawa mimik muka seseorang itu dapat memberikan sekurang-kurangnya sepuluh kelompok makna, iaitu kebahagiaan, terkejut, ketakutan, ketakjuban, kesedihan, kemuakan, mengecam, kemarahan, minat dan tekad. Hal ini dapat diperlihatkan melalui Hikayat Putera Jayapati seperti petikan teks berikut:

(Maka) maka fikir di dalam hatinya tuan puteri, 'Jika sudah pulang Putera Jayapati, / tiadalah dapat aku mencahari suami yang demikian ini.' Maka hati tuan puteri pun berdebar-debar seperti hendak menangis, mukanya pun merah seperti bunga raya dan segala dayang-dayang pun kepiluan-piluan menengar kata itu. Maka tuan puteri pun menyuruh mengunjukkan puannya sambil berpantun. (Hikayat Putera Jayapati, 2004:34)

Penelitian terhadap petikan teks ini menujukkan berlakunya proses komunikasi emosi antara watak Puteri Indera Nurlaila dengan dayangdayang. Hal ini dapat diperlihatkan menerusi isyarat muka tuan puteri dalam mengekspresikan emosi malu dan sedih, iaitu mukanya pun merah seperti 
bunga raya. Ketika itu, Putera Jayapati dikhabarkan akan pulang semula ke negerinya. Hal ini bermakna tuan puteri tidak akan bertemu lagi dengan Putera Jayapati. Oleh sebab itulah, tuan puteri menahan rasa sedih dalam dirinya. Hal ini amat bertepatan dengan Teori Kognitif Arnold-Ellis yang menjelaskan bahawa rangsangan luar seperti peristiwa pemergian Putera Jayapati telah menimbulkan emosi dalam diri tuan puteri. Emosi sedih yang dialami jelas dipaparkan menerusi reaksi mimik mukanya.

Dalam masa yang sama tuan puteri juga menahan rasa malu ketika bertentangan mata dengan Putera Jayapati. Hal ini kerana tuan puteri turut menyimpan perasaannya terhadap Putera Jayapati. Dalam hal ini, Wan Rose Eliza, Noor Shakirah \& Syed Muhammad Azhan (2005: 522) menjelaskan bahawa malu secara umumnya merupakan satu sifat individu yang ingin menyembunyikan sesuatu kerana takut diketawakan. Jika diperhatikan teks ini, didapati bahawa dayang-dayang juga turut tersentuh dengan kata-kata dan ekspresi wajah tuan puteri. Ekspresi wajah tuan puteri yang merah itu dibandingkan seperti warna bunga raya yang menggunakan teknik simile, iaitu perbandingan atau perumpamaan bahasa kiasan yang menyamakan kata-kata pembanding. Misalnya, seperti, bak, bagai, laksana dan kata pembanding yang lain (Rachmat Djoko Pradopo, 2000: 62). Oleh yang demikian, berdasarkan petikan teks ini telah membuktikan bahawa wujudnya komunikasi emosi malu dan sedih yang diperlihatkan melalui wajah tuan puteri.

Komunikasi bukan lisan berbentuk kinesik melalui wajah juga turut diperlihatkan di dalam teks Hikayat Si Miskin. Namun begitu, dalam teks ini memerihalkan bentuk komunikasi emosi marah. Jika diperhatikan contoh petikan ini jelas menunjukkan wujudnya komunikasi emosi marah melalui ekspresi wajah.

Maka sembah segala ahlun-nujum itu sekaliannya, "Ya Tuanku Syah Alam, adapun selagi hidup anakanda dua bersaudara itu nescaya Duli Yang Dipertuan tiada kekal di atas takhta kerajaan, sebab anakanda kedua itu terlalu sangat besar celakanya." Maka, baginda itu pun dahsyat mendengar sembah segala ahlun-nujum itu. Maka, baginda itu pun memberi persalinan akan segala ahlun-nujum itu serta dengan merah padam warna mukanya. Maka, segala ahlun-nujum itu pun menundukkan kepalanya serta dengan takutnya lalu bermohon kembali pulang ke negerinya. (Hikayat Si Miskin, 2016:12)

Berdasarkan petikan teks ini proses komunikasi emosi melalui wajah Maharaja Indera Angkasa yang menahan rasa marah setelah diberitahu tentang tilikan ahli nujum berkaitan dengan anaknya, iaitu Marakarmah 
dan Tuan Puteri Nila Kesuma. Ahli nujum memberitahu bahawa kedua-dua anakandanya akan membawa malapetaka dan musibah kepada takhta kerajaan. Setelah baginda menerima perkhabaran tersebut, baginda mengekspresikan emosi marahnya melalui wajahnya yang merah padam warna mukanya kerana menahan rasa amarah. Keadaan ini amat bertepatan dengan teori kognitif yang dikemukakan oleh Arnold-Ellis bahawa rangsangan luaran watak Maharaja Indera Angkasa yang menerima ramalan buruk mengenai kedua-dua anaknya telah dihantar ke talamus untuk diproses dan akhirnya terbentuklah emosi marah. Setelah itu, emosi marah itu dijelmakan menerusi mimik muka yang merah padam.

Ketika itu juga, wujudnya proses komunikasi emosi apabila ahli nujum menundukkan kepala kerana takut dan memohon untuk mengundurkan diri. Walaupun tidak menggunakan sebarang kata-kata lisan tetapi, proses komunikasi emosi tetap berlaku seperti yang diperlihatkan dalam petikan teks ini. Menurut Rozaimah dan Nor Hashimah (2015: 252), faktor persekitaran kognitif dan pengalaman badaniah serta perbezaan pengalaman, budaya dan adat resam pula telah mewujudkan pelbagai metafora konsepsi marah. Misalnya dalam bahasa Melayu seperti marah ialah warna merah. Hal ini bermaksud emosi marah biasanya dikaitkan dengan warna merah seperti yang diperihalkan dalam petikan teks ini.

\section{Bentuk Kinesik melalui Sentuhan}

Manusia memerlukan sentuhan untuk memenuhi kehendak psikologi. Sentuhan anggota badan khususnya tangan dapat menggambarkan hubungan antara individu. Berjabat tangan, berpelukan, berpimpin tangan, menepuk bahu merupakan beberapa contoh sentuhan yang mempunyai mesej tertentu. Melalui sentuhan, manusia dapat mentafsirkan emosi seseorang. Sentuhan juga dapat menggambarkan kemesraan, kasih sayang dan pengharapan (Mohd Baharudin \& Mohd Khairie, 2015: 68). Dalam nashkah Melayu tradisional misalnya, memerihalkan komunikasi bukan lisan berbentuk sentuhan sesama watak dalam meluahkan emosi. Perhatikan petikan teks Hikayat Putera Jayapati seperti yang berikut:

Maka Putera Jayapati pun tunduk berlinang-linang air matanya, lalu ia sujud pada kaki gurunya itu menyembah dan berjabat tangan serta minta ampun. Maka segala anak raja-raja itu pun datanglah dan berjabat tangan dengan Putera Jayapati dan berpeluk bercium serta tangisnya. Setelah sudah, maka kata Putera Jayapati, "Tinggallah saudaraku sekalian, mana 
yang salah bebal hamba, janganlah saudaraku ambil di hati sudaraku kesemuanya." (Hikayat Putera Jayapati, 2004: 16)

Hasil dapatan terhadap petikan teks ini membuktikan wujudnya komunikasi emosi bukan lisan antara watak Putera Jayapati dengan guru dan anak rajaraja. Berdasarkan Teori Kognitif Arnold-Ellis, rangsangan luaran, iaitu peristiwa perpisahan antara mereka telah mewujudkan suasana suram dan hiba. Pembentukan emosi tersebut merupakan hasil daripada proses rangsangan luar dan kemudiannya dijelmakan melalui perilaku watak sebagai tindak balas kepada emosi yang dialami. Kesedihan mereka itu dapat digambarkan melalui sentuhan seperti berjabat tangan dan berpeluk serta bercium. Sentuhan itu dapat ditafsirkan sebagai salah satu bentuk komunikasi emosi bukan lisan. Emmert dan Donaghy dalam Noor Afzaliza Nazira, Maizatul Haizan dan Abdul Latiff (2018: 112) menjelaskan bahawa sentuhan atau hubungan badan merupakan cara terbaik untuk menyampaikan sikap peribadi, baik positif dan negatif. Kekerapan sentuhan juga boleh menjadi petunjuk persahabatan dan keinginan dalam kalangan orang yang melakukannya seperti berjabat tangan, memeluk, mencium tangan, menumbuk, menampar dan mengusap kepala. Oleh yang demikian, komunikasi emosi melalui sentuhan seperti berjabat tangan, berpeluk dan bercium yang terpancar dalam petikan teks ini membuktikan bahawa wujudnya hubungan persahabatan yang erat antara watak-watak tersebut. Perhatikan pula petikan teks dalam Hikayat Si Miskin seperti yang berikut:

Maka kata Maharaja Marakarmah itu, "Jikalau demikian bukanlah anak mamak itu yang celaka rupanya." Maka sahut keduanya, "Benarlah kata tuan itu," sambil ia menangis laki isteri seraya katanya, "Jikalau ada lagi hidup adalah seperti orang muda besarnya." Maka Maharaja Marakarmah pun berkata pula, "Tiadalah hamba bertemu, tetapi ada hamba bertemu dengan mayat orang sudah hilang matanya. orang itu di tengah rimba." Maka, keduanya itu pun menangislah laki isteri tersedih-sedih hendak berjalan pergi melihat mayat itu. Maka, segeralah dipegangkan oleh Marakarmah itu tangannya seraya katanya, "Diamlah tuan jangan menangis, bukannya anak mamak, kerana rambutnya sudah putih oleh uban.” Maka, barulah ia diam... (Hikayat Si Miskin, 2016: 59)

Berdasarkan petikan menunjukkan komunikasi emosi melalui sentuhan tangan seperti yang digambarkan melalui perilaku Marakarmah yang memegang tangan kedua-dua suami isteri itu. Sentuhan pegangan tangan itu sebagai respons kepada komunikasi emosi yang terpancar melalui 
watak kedua-dua suami isteri. Suasana hiba dan pilu itu telah menjentik emosi Marakarmah yang turut merasai kesedihan pasangan suami isteri itu. Menurut Teori Kognitif Arnold-Ellis, individu memproses rangsangan luaran yang dialaminya sehingga terbentuknya emosi. Pembetukan emosi individu diperlihatkan melalui perilakunya yang bertindak balas terhadap rangsangan luaran atau peristiwa yang dialaminya. Hal ini amat jelas dilihat melalui gambaran peristiwa pertemuan semula antara Marakarmah dengan kedua-dua ayahanda dan bondanya. Ketika itu, berlakunya proses rangsangan luaran yang menghasilkan emosi sedih. Emosi watak jelas dipaparkan menerusi perilaku sentuhan tangan watak yang merupakan respons kepada emosi yang dirasainya.

Sentuhan tangan itu juga bertujuan untuk memujuk dan mengurangkan beban emosi kedua-dua suami isteri itu. Menurut Azlina (2015: 68), salah satu teknik pemujukan adalah dengan memberikan maklum balas empati. Empati merupakan keadaan yang membolehkan seseorang turut merasai emosi dan perasaan orang lain. Ketika berlakunya komunikasi dalam sesebuah perhubungan, pendengar perlu memahami, menyambut dan mengemukakan perkara yang difahaminya. Pendengaran empati berlaku apabila pendengar memahami perasaan dan situasi orang lain dengan sepenuhnya dan secara mendalam, emosi dan intelek dan memberikan respons yang sewajarnya. Oleh yang demikian, terbuktilah bahawa sentuhan tangan Marakarmah merupakan satu bentuk komunikasi emosi yang menimbulkan rasa empati dalam dirinya.

\section{Bentuk Kinesik Melalui Gerakan Anggota Badan}

Menurut Mohd Baharudin dan Mohd Khairie (2015:69), komunikasi bukan lisan melalui gerakan badan dan tangan dikenali sebagai gestural. Melalui gerakan badan, gerak tangan, cara berdiri, cara duduk boleh menggambarkan tingkah laku seseorang seperti mendorong-menghalang, bertindak balas pasif, perasaan positif atau negatif. Selain itu, pengerakan anggota tubuh badan atau bahasa tubuh dapat memerihalkan emosi seseorang. Hal ini bermakna manusia juga berkomunikasi menerusi bahasa tubuh untuk berkongsi dan mempamerkan emosi yang dialaminya ketika itu. Selain itu, Mahmood Nazar (2018: 326) menjelaskan bahawa salah satu cara untuk membantu mengenali emosi dengan menggunakan komunikasi tanpa bahasa adalah dengan pergerakan anggota tubuh manusia. Apabila manusia beremosi, terdapat perbezaan yang ketara antara pergerakan anggota tubuh badan manusia. Perhatikan contoh kedua-dua teks yang berikut: 
Maka pada ketika itu, tuan puteri pun baharulah bangun daripada beradu itu serta dengan Putera Jayapati. Maka inangda pun meniarap di kaki tuan puteri serta dengan tangisnya, lalu berdatang sembah, "Ampun tuanku beribu-ribu ampun. Bolehkah kata patik hamba tuha ini, janganlah tuanku kedua ini lagi bermain. / Adapun sekarang ini hilanglah cahaya mata patik dan hilanglah jujungan kepala patik dan hilanglah nyawa badan patik." Setelah sudah, maka tuan puteri pun terkejutlah melihat lakunya mak inang itu serta katanya, "Hai mak inang, apa mulanya maka demikian ini? Berilah tahu kepada beta." (Hikayat Putera Jayapati, 2004:40)

... Maka, Tuan Puteri pun tiadalah berdaya lagi lalu sujud kepada kaki baginda dengan tangisnya. Maka sembahnya, "Ya Tuanku, adapun patik ini dibuangkan oleh orang dua bersaudara ke dalam hutan tiada makan dan tiada minum, hanyalah yang patik makan itu taruk kayu dan umbut yang muda-muda sahaja..."...Maka segala yang mendengar itu pun menangislah terlalu belas hatinya. Maka bondanya itu pun memeluk Tuan Puteri seraya katanya, "Ada juga rupanya saudara tuan, mengapakah maka tiada tuan katakan kepada bonda sekian lama ini, maka tuan duduk dalam percintaan selama ini?” (Hikayat Si Miskin, 2016:27)

Jika diperhatikan petikan kedua-dua teks ini memperlihatkan komunikasi bukan lisan melalui gerakan anggota badan seperti meniarap dan sujud. Dalam Hikayat Putera Jayapati misalnya, pengerakan anggota badan meniarap merupakan refleksi kepada perasaan sedih dan bimbang yang dialami oleh watak inangda dan tuan puteri ketika itu sehingga menyebabkan watak-watak disekelilingnya berasa terkejut dan telah menimbulkan tanda tanya. Misalnya, watak inangda bimbang dengan keadaan tuan puteri yang berdua-duaan dengan Putera Jayapati sedangkan tuan puteri merupakan tunangan orang. Kebimbingan inangda itu jelas diperlihatkan melalui perilaku meniarap dalam mengekspresikan emosinya. Berdasarkan Teori Kognitif ArnoldEllis, pembentukan emosi terhasil daripada rangsangan luaran yang jelas diperlihatkan melalui perilaku individu. Hal ini amat jelas sekali seperti yang digambarkan melalui watak inangda yang meniarap. Perilaku meniarap merupakan tindak balas kepada emosi yang terbentuk, iaitu emosi sedih dan bimbang hasil proses daripada rangsangan luaran watak.

Begitu juga dalam Hikayat Si Miskin yang diperlihatkan menerusi watak Tuan Puteri Mayang Mengurai (Tuan Puteri Ratna Kemala) yang bimbang akan keadaan saudaranya Marakarmah yang masih belum ditemuinya. Kebimbangan itu jelas terpancar melalui perilaku sujud yang menunjukkan proses komunikasi bukan lisan. Hal ini seperti yang diperkatakan oleh 
Mohd Baharudin dan Mohd Khairie (2015:69) bahawa salah satu kategori gestural ialah penyesuaian yang bermaksud gerakan anggota badan dalam menggambarkan penyesuaian diri seseorang dengan emosi atau rangsangan dalaman dirinya apabila menghadapi masalah dan kebimbangan. Jelaslah bahawa gerakan anggota badan meniarap dan sujud merupakan salah satu bentuk komunikasi bukan lisan dalam memerihalkan kebimbangan dan masalah yang dihadapi watak ketika itu.

\section{Bentuk Kinesik melalui Tingkah Laku Luar Kawalan}

M. Darwis Hude (2006:53) menyatakan bahawa bagi kes-kes berat biasanya akan mengalami kejutan yang teruk atau tidak sedarkan diri (pengsan). Sebahagiannya orang mungkin melatah atau menyebut kata-kata tertentu ketika terkejut. Emosi yang menyebabkan seseorang itu pengsan atau tidak sedarkan diri tidak hanya menunjukkan emosi negatif semata-mata. Hal ini kerana terdapat juga peristiwa seperti pertemuan semula yang mempamerkan emosi positif akibat terlalu gembira sehingga menyebabkan seseorang itu tidak sedarkan diri. Pemerhatian terhadap kedua-dua naskhah memperlihatkan wujudnya komunikasi bukan lisan melalui tingkah laku luar kawalan. Yang berikut ialah contoh petikan tersebut:

Sebermula, akan rupa Malik Indera pun bercahaya-cahaya sebab terkena sinar muka Putera Jayapati itu. Maka dayang-dayang itu pun hairanlah serta tercengang-cengang, tiada terkata-kata. Maka segera ditegur oleh Malik Indera katanya, "Hendak ke mana hai dayang-dayang?" Maka kata dayang-dayang itu, hamba disuruh oleh tuan puteri memanggil tuan hamba. Maka dayang-dayang itu pun rebah pengsan. Maka Malik Indera pun segera menyapu air ke muka dayang-dayang itu. Setelah sudah, maka dayang-dayang itu pun sedarlah, lalu bangkit serta dengan letih lesunya. Maka diusung orang bawa kembali kepada tuan puteri. Serta sampai, maka tuan pun bertanya, "Apa sebabnya, maka dayang-dayang demikian ini lakunya." Maka diceterakan Malik Indera segala hal / ehwalnya itu kepada tuan puteri. (Hikayat Putera Jayapati, 2004:23)

Setelah didengar oleh Tuan Puteri akan titah baginda itu, maka ia pun rebah pengsan tiada khabarkan dirinya. Setelah ia ingat dari pengsannya itu, maka ia pun menangislah terlalu sangat seraya katanya, "Sampai hati kakanda melihat darahnya berhamburan itu. Jikalau sangat benci akan dia suruhlah ia pergi barang ke mana, tetapi pada bicara adinda selama kita beranak ini adalah beroleh kebajikan oleh sebabnya itu juga." Maka 
titah baginda, "Jikalau engkau tiada mahu menyuruhkan anakmu itu pergi, biarlah kubunuh sekarang juga.” (Hikayat Si Miskin, 2016:12)

Berdasarkan kedua-dua teks yang dikaji menunjukkan berlakunya proses komunikasi bukan lisan melalui tindakan luar kawalan seperti rebah pengsan dan rebah pengsan tiada khabarkan dirinya. Kedua-dua teks ini membuktikan bahawa watak-watak tersebut mengalami emosi terkejut sehingga menyebabkan mereka tidak sedarkan diri. Rasa terkejut itu ialah tindak balas terhadap perkara yang dilihat dan dialaminya ketika itu. Misalnya dalam Hikayat Putera Jayapati diperlihatkan menerusi watak dayang-dayang yang rebah pengsan setelah terkejut melihat rupa paras Putera Jayapati yang bercahaya. Keadaan pada ketika itu telah menimbulkan tanda tanya kepada watak-watak yang berada disekelilingnya. Begitu juga dengan watak tuan puteri dalam Hikayat Si Miskin yang berasa terkejut dan sedih sehingga rebah pengsan tiada khabarkan dirinya setelah mengetahui kedua-dua anakandanya akan dihalau keluar kerana dikatakan membawa bencana dan malapetaka kepada negeri. Dalam hal ini, Sohaimi (2012: 161) menjelaskan bahawa rebah (pengsan) tiada khabar akan diri merupakan unsur hiperbola untuk menunjukkan rasa sedih yang amat sangat. Jelaslah bahawa kedua-dua teks yang dikaji ini memerihalkan wujudnya proses komunikasi emosi melalui tingkah laku luar kawalan. Keadaan ini juga amat bertepatan dengan Teori Kognitif Arnold-Ellis yang amat menekankan bahawa rangsangan luaran manusia akan membentuk emosi yang akan diperlihatkan melalui perilaku manusia. Kedua-dua peristiwa tersebut membuktikan bahawa rangsangan luaran watak telah menyebabkan terbentuknya emosi terkejut. Emosi yang dialami itu amat ketara dilihat melalui perilaku rebah pengsan yang menjadi tindak balas kepada emosi terkejut watak.

\section{KESIMPULAN}

Dalam hal membicarakan tentang unsur emosi sebagai komunikasi bukan lisan dapat dibuktikan menerusi kedua-dua naskhah, iaitu Hikayat Putera Jayapati dan Hikayat Si Miskin. Pembentukan emosi yang dipaparkan dalam kedua-dua teks juga menepati elemen-elemen yang terkandung dalam Teori Kognitif Arnold-Ellis. Selain itu, komunikasi bukan lisan berbentuk kinesik juga amat menepati bentuk-bentuk kinesik seperti yang diperihalkan oleh Mohd Baharudin Othman dan Mohd Khairie Ahmad serta M. Darwis Hude. Antaranya termasuklah isyarat mata, wajah, sentuhan, gerakan anggota badan dan tingkah laku luar kawalan. Komunikasi bukan lisan amat berbeza dengan 
komunikasi lisan terutamanya dalam hal memerihalkan emosi manusia. Namun begitu, komunikasi bukan lisan yang berbentuk kinesik mampu untuk menterjemah dan mentafsirkan emosi manusia yang meliputi keseluruhan bahasa badan manusia. Oleh itu, adalah wajar mengetengahkan kajian emosi yang menjadi medium perantaraan komunikasi manusia kerana manusia saban hari saling berhubung antara satu sama lain. Malah, manusia juga tidak dapat lari daripada mengekspresikan emosinya terhadap peristiwa atau situasi yang dialaminya. Oleh sebab itulah, manusia juga saling bertukar dan berkongsi emosi dalam berkomunikasi. Selain itu, diharapkan agar kajian mengenai komunikasi emosi dapat diperluas kajiannya terutamanya dalam naskhah-naskhah yang lain.

\section{RUJUKAN}

Abdul Mua'ti@ Zamri Ahmad. (2016).Psikologi dalam Komunikasi. Kuala Lumpur: Dewan Bahasa dan Pustaka.

Abu Bakar Hamid. (2016). Hikayat Si Miskin. Kuala Lumpur: Dewan Bahasa dan Pustaka. Afidatul Syazwani Afandi, Norazimah Zakaria \& Abdul Halim Ali. (2020). Magis dan Aspek Kelegaan Jiwa Berdasarkan Perspektif Emosi Hiran dalam Hikayat Marakarmah. Jurnal Peradaban Melayu, 15, 10-21. https://doi.org/10.37134/ peradaban.vol15.2.2020

al-Awaisyah, Syeikh Husain. (2009). Menangis Kerana Takut Kepada Allah. Terj. Ummu Abdillah al-Buthoniyah. Maktabah Raudhah al-Muhibbin (e-book). http://www.raudhatulmuhibbin.org

Ali Ahmad dan Siti Hajar Che Man. (2005). Emosi di dalam Karya Bercorak Islam. Dlm. Hashim Awang (Ed.) et. al., Emosi Melayu (pp. 22-35). Kuala Lumpur: Akademi Pengajian Melayu, Universiti Malaya.

Azlina Kamaruddin. (2015). Komunikasi dan Seni Pemujukan. Sintok: Penerbit Universiti Utara Malaysia.

Chen N. F. dan Mawar Safei. (2017). Cinta: Komunikasi Emosi Wanita dalam Novel China dan Melayu. Jurnal Melayu. Isu Khas, 334-353.

Goleman, D. (2006). Emotional Intelligence. New York. Bantam Dell.

Intan Putri. (2018). Komunikasi Non Verbal (Makna Kinesik) Pesulap dalam Pertunjukan Sulap Mata. Syi'ar. 18(1), 56-73.

Ismail Yusoff. (2008). Kesusateraan Melayu Lama dan Baru. Sintok: Penerbit Universiti Utara Malaysia.

Johnson-Laird, P. N. dan Oatley, K. (2010). Emotions, Music and Literature. Dlm. Lewis, M. (Ed.) et. al. Handbook of Emotions. New York: The Guiford Press.

M. Darwis Hude. (2006). Emosi: Penjelajahan Religio-Psikologis Tentang Emosi Manusia di dalam Al-Quran. Jakarta: Penerbit Erlangga. 
Mahmood Nazar Mohamed. (2018). Pengantar Psikologi. Kuala Lumpur: Dewan Bahasa dan Pustaka.

Maznida Mahadi \& Tengku Intan Marlina Tengku Mohd Ali. (2018). Perbandingan Dominasi Bentuk Emosi Lelaki dalam Novel Penyeberang Sempadan dengan Kafka on the Shore. Jurnal Pengajian Melayu. 29(1), 30-50.

Meydian Effendy dan Endang Sri Indrawati. (2018). Hubungan Antara Empati dengan Perilaku Agresif pada Suporters Sepakbola Panser Biru Banyumanik Semarang. Jurnal Empati. 7(3),140-150.

Mohd Baharudin Othman \& Mohd Khairie Ahmad. (2015). Pengantar Komunikasi. Sintok: Penerbit Universiti Utara Malaysia.

Noor Afzaliza Nazira Ibrahim, Maizatul Haizan Mahbob \& Abdul Latiff Ahmad. (2018). Kepentingan Komunikasi Non Verbal dalam Organisasi. E-Bangi Journal of Social Sciences and Humanities. 15(5), 107-116.

Normaliza Abd Rahim, Siti Nur Aliaa Roslan dan Nur Maisarah Roslan. (2017). Konflik Emosi dalam Lirik Lagu 'Nipah oh Nipah.' Mahawangsa. 4(1), 89-98.

Nurul Afifah Adila Mohd Salleh dan Normaliza Abd Rahim. (2016). The Expression of Emotion in Selected Modern Poems. Malay Literature. 29(2), 250-267.

Oatley, K. (2006). Understanding Emotion. United Kingdom: Blackwell Publishing Ltd.

Othman Yatim dan Abd. Aziz Rashid. (2005). Peranan Emosi dalam Pengkaryaan Hasil Seni. Dlm. Hashim Awang (Ed.) et. al., Emosi Melayu (pp. 388-393). Kuala Lumpur: Akademi Pengajian Melayu, Universiti Malaya.

Rachmat Djoko Pradopo. (2000). Pengkajian Puisi Analisis Strata Norma dan Analisis Struktural Semiotik. Yogyakarta: Gadjah Mada University Press.

Ramli Hassan. (1990). Pengantar Psikiatri. Kuala Lumpur: Dewan Bahasa dan Pustaka. Reeve, J. (2009). Understanding Motivation and Emotion. New Jersey: John Wiley $\&$ Sons. Inc.

Rozaimah Rashidin \& Nor Hashimah Jalaluddin. (2015). Metafora Konsepsi Marah dalam Data Korpus Teks Tradisional Melayu. Seminar Linguistik Kebangsaan (SLiK2015). Kuala Lumpur: Dewan Bahasa dan Pustaka.

Salmah Jan Noor Muhammad. (2018). Interpersonal Communication as a Solution for Resolving Diplomatic Conflicts in the Malay Sultanates. Malay Literature. 31(1), 47-68.

Sohaimi Abdul Aziz. (2012). Duka Sebagai Satu Ekspresi Sastera: Estetika Syairsyair Terpilih. Dlm. Muhammad Haji Salleh (Ed.) Pandangan Dunia Melayu Pancaran Sastera (pp. 138-175). Kuala Lumpur: Dewan Bahasa dan Pustaka.

Wahyunah Abd. Gani. (2004). Hikayat Putera Jayapati. Kuala Lumpur: Dewan Bahasa dan Pustaka.

Wan Rose Eliza Abd. Rahman, Noor Shakirah Mat Akhir dan Syed Muhammad Azhan Syed Hassan. (2005). Penggunaan Ironi dan Kaitannya dengan Malu Orang Melayu Mengikut Perspektif Islam. Dlm. Hashim Awang (Ed.) et. al., Emosi Melayu (pp. 514-526). Kuala Lumpur: Akademi Pengajian Melayu, Universiti Malaya. 